\title{
Determination of Mercuric Ion in Water Samples with a LED Exciting and CCD Based Portable Spectrofluorimeter
}

\author{
Arsenio Muñoz de la Peña ${ }^{{ }^{*}}$, María Isabel Rodríguez-Cáceres ${ }^{1}$, Diego Bohoyo Gil ${ }^{1}$, \\ María del Carmen Mahedero ${ }^{1}$, María del Carmen Hurtado-Sánchez ${ }^{1}$, Reyes Babiano ${ }^{2}$ \\ ${ }^{1}$ Department of Analytical Chemistry, University of Extremadura, Badajoz, Spain \\ ${ }^{2}$ Department of Organic and Inorganic Chemistry, University of Extremadura, Badajoz, Spain \\ E-mail:"arsenio@unex.es \\ Received March 29, 2011; revised June 3, 2011; accepted June 15, 2011
}

\begin{abstract}
The fluorescent characteristics of a fluorimetric chemosensor for mercuric ion, $\mathrm{Hg}^{2+}$, employing a synthesized Rhodamine 6G derivative, have been analyzed. For that, a portable spectrofluorimeter composed of a $515 \mathrm{~nm}$ LED as excitation source, two fiber-optics and a CCD camera as detector, has been used, intended for "in situ" analysis. A highly selective Rhodamine based probe for $\mathrm{Hg}^{2+}$, that is water soluble and gives a positive response upon analyte binding, is reported. The reagent is bearing a monothiospirolactone group in a Rhodamine $6 \mathrm{G}$ architecture and the thiol atom served for the direct attack of thiophilic $\mathrm{Hg}^{2+}$. The fluorescence enhancement is attributed to the spirolactone ring opening and the coordination of two sulphur atoms to $\mathrm{Hg}^{2+}$ giving a 2:1 reagent: $\mathrm{Hg}^{2+}$ stoichiometry complex.
\end{abstract}

Keywords: Chemosensor, LED, Mercuric Ion, Water Analysis

\section{Introduction}

Mercury is widely distributed in the air, water and soil, and is considered by the Environmental Protection Agency (EPA) to be a highly dangerous element because of its severe inmunotoxic, genotoxic and neurotoxic effects [1]. It is generated by volcanic emission and in several human activities as gold mining, combustion of solid waste or burning of fossil fuels. The great time of residence of mercury in vapour state and his easy oxidation to inorganic species of $\mathrm{Hg}^{2+}$ soluble in water have caused environmental $\mathrm{Hg}^{2+}$ levels. Mercury easily passes through biological membranes such as skin, respiratory and gastrointestinal tissues. When absorbed in human body, mercury causes damage to the central nervous and endocrine systems as well as neurological irreversible damages. The toxicity of mercury is known to be highly dependent on its chemical form: organomercury is generally more toxic than inorganic mercury salts [2].

Recently, a variety of selective and sensitive fluorescent $\mathrm{Hg}^{2+}$ chemosensors have been developed based on fluorescein derivatives [3-6], $\mathrm{NO}_{2} \mathrm{~S}_{2}$-donor macrocyle [7], naphthalimide [8,9], BODIPY [10-12] or Rhodamine derivatives [13-23].

BODIPY (boron dipyrromethene) fluorophores have been widely used for the determination of $\mathrm{Hg}$ (II). Those fluorophores have high absorption coefficient $(\varepsilon>50000$ $\left.\mathrm{M}^{-1} \mathrm{~cm}^{-1}\right)$, high fluorescence quantum yield $(\Phi>0.5)$, and high photostability [24]. Polyamide receptor photoelectron transfer (PET) based fluorescent sensor molecules could be used to detect $\mathrm{Hg}^{2+}$ ions with either fluorescence off-on response or fluorescence colour change [8]. J. Wang et al. used a series of polyamide receptors incorporating two, three and four amide arms to the BODIPY fluorophore. They observed that a clear emission turn-on response when as low as $2 \mathrm{ppb}$ (content limit in drinking water set by EPA) of $\mathrm{Hg}(\mathrm{II})$ are present. Thus, the sensor is practical as $\mathrm{Hg}^{2+}$ ion "annunciator" for drinking water [10]. On the other hand, J. Du et al. synthesized a highly selective PET fluorescent sensor for $\mathrm{Hg}^{2+}$ containing a BODIPY fluorophore and a $\mathrm{NS}_{2} \mathrm{O}_{2}$ pentachelating receptor. With this sensor the $\mathrm{Hg}^{2+}$ could be detected in a wide $\mathrm{pH}$ range [11]. Also, thiacrown and crown ethers have been appended to BODIPY fluorophores [12].

Rhodamines are classic dyes/fluorophores whose photochemical properties have already been well studied. Because of their low cost, long-wavelength $(>500 \mathrm{~nm})$ absorption/emission and high molar absorption coefficient and quantum yield, these fluorophores are usually util- 
ized as reporting groups in routine optical analysis. The metal ion sensing behaviour of these rhodamine-based optical sensors is very interesting. Typically, in the absence of metal ions, the sensor molecules prefer their spirolactam ring-closed state, which shows little absorption or fluorescence in the visible range $(400-700 \mathrm{~nm})$. However, upon the addition of specific metal ions, the chelating or reaction of metal ions with sensor molecules will simultaneously open the spirolactam ring and make the sensors converted into their ring-opened state, which is highly absorbent and fluorescent above $500 \mathrm{~nm}$ [25]. Y.-K. Yang et al. have developed a rhodamine-based fluorescent and colorimetric chemodosimeter for the rapid detection of $\mathrm{Hg}$ ions in aqueous media. The selectivity of the system for mercuric ion over other metal ions is remarkably high, and its sensitivity is below $2 \mathrm{ppb}$ in aqueous solution [13]. On the other hand, a rhodamine thiospirolactone chemosensor was developed by X.-Q. Zhan et al. [14] for the selective and sensitive reversible sensing of $\mathrm{Hg}^{2+}$. W. Shi and H. Ma develop a rhodamine $\mathrm{B}$ thiolactone for $\mathrm{Hg}^{2+}$ in neutral solution with good linearity between 0.5 and $5 \mu \mathrm{M}$ and detection limit 20 nM [15]. S.-K. Ko et al. develop a rhodamine-based molecular probe for in vivo monitor mercury ions in living cells and vertebrate organisms in aqueous media. The results of the experiments shown that the chemosensor responds selectively to mercury ions over other metal ions and it is possible to detect the accumulation of mercury ions in zebrafish tissue and organs [16]. A rhodamine $\mathrm{B}$ thiohydrazide assay has been developed by $\mathrm{H}$. Zheng et al. in which $\mathrm{Hg}(\mathrm{II})$ could be detected fluorimetrically at least down to $5.0 \times 10^{-8} \mathrm{M}$ [17]. Finally, H.N. Kim et al. developed a method to determine mercury in vivo in the nematode Caenorhabditis elegans, previously incubated with $\mathrm{Hg}\left(\mathrm{ClO}_{4}\right)_{2}$ in concentrations of $\mathrm{Hg}^{2+}$ comprised between $1 \mathrm{~nm}$ and $1 \mu \mathrm{M}$ [19].

Moreover, Rhodamine has been employed to determine organic derivatives of mercury such as methylmercury. This compound is produced by aquatic microorganism from inorganic mercury and is one of the most toxic species of mercury. Methylmercury passes through biological membranes causing severe damage to various tissues and organs humans. So, Yang et al. [20] have been developed a method to determine this compound with a rhodamine hydrazide derivative. The analysis is based in the desulfurization of the derivative in presence of methylmercury and formation of the cyclic fluorescent compound, and the method was applied in zebrafish. The same chemosensor was used by Muñoz de la Peña et al. for the determination of $\mathrm{Hg}^{2+}$ in water and fish samples $[21,22]$.

Recently, derivatives for determination of mercury have been developed from rhodamine in combination with pyrene [23]. The use of pyrene provided a derivative with excellent spectroscopic properties such as high molar absorption coefficients and high fluorescence quantum yields.

The semiconductor light sources, as laser diodes (LDs) and ultrabright light emitting diodes (LEDs), are a huge improvement in fluorescence applications. LED is a semiconductor p-n junction device, which emits light in a narrow spectrum, produced by a form of electroluminescence [26]. LEDs are cheap and commercially available from $350 \mathrm{~nm}$ to the near infrared. LEDs with different colours and white light have been developed. Highbrightness LEDs are becoming increasingly important because of their potential applications. Light is generated from the active region of LED spontaneously in all directions and escape from LED die. Commercially manufactured LEDs consists of a small point like light emitting active area typically $\approx 1 \mathrm{~mm}^{2}$ surrounded by high refractive-index semiconductor surface shape [27]. A general overview of LDs and LEDs is given by Landgraf [28]. Among other applications, different LEDs and filter combinations have been tested for the analysis of crude oil fluorescence.

In the work described here, a LED based spectrofluorimeter combined with fiber-optics and a CCD detector has been tested, in order to check its selectivity and sensitivity for the determination of mercuric ion in aqueous samples, using a highly selective synthesized monothiospirolactone Rhodamine $6 \mathrm{G}$ derivative.

\section{Experimental Procedures}

\subsection{Synthesis and Characterization of Rhodamine-Derivative I}

Rhodamine derivative I was synthesized by a similar procedure, which has been already reported [29]. Rhodamine $6 \mathrm{G}$ (R6G) (3 g, $6.3 \mathrm{mmol})$ was added to the solution of $\mathrm{NaOH}(4.8 \mathrm{~g}, 0.12 \mathrm{~mol})$ in ethanol $(30 \mathrm{~mL})$ and water $(60 \mathrm{~mL})$. After refluxed for $12 \mathrm{~h}$, the reaction mixture was cooled and ethanol was evaporated in vacuo, then adjusted $\mathrm{pH}$ to $6-7$ using hydrochloric acid $(2 \mathrm{M})$. The formed precipitate was filtered, washed several times with water and dried to give $2.88 \mathrm{~g}$ Rhodaminederivative II as a red solid (yield 96\%).

To a stirred solution of II ( $2 \mathrm{~g}, 4.8 \mathrm{mmol})$ in 1,2-dichloroethane $(15 \mathrm{~mL})$, phosphorus oxychloride $(3 \mathrm{~mL})$ was added dropwise. After refluxed for $4 \mathrm{~h}$, the reaction mixture was cooled and evaporated in vacuo. The crude acid chloride was dissolved in THF $(6 \mathrm{~mL})$, and the resulting solution was then added dropwise to a mixed solution of thiourea $(1.52 \mathrm{~g}, 20 \mathrm{mmol})$ and triethylamine $(12 \mathrm{~mL})$ in THF $(50 \mathrm{~mL}) /$ water $(10 \mathrm{~mL})$ at room temperature. After stirring over night, the solvent was re- 
moved under reduced pressure. Then, $50 \mathrm{~mL}$ of water was added, and the formed precipitate was filtered. The precipitate was washed several times with water and dried. The crude product was purified by silica-gel column chromatography with $\mathrm{CH}_{2} \mathrm{Cl}_{2}$ as eluent, affording $1.0 \mathrm{~g}$ of Rhodamine-derivative I (yield 50\%).

The structure of Rhodamine-derivative I was confirmed by ${ }^{1} \mathrm{H}$ NMR and ${ }^{13} \mathrm{C}$ NMR. ${ }^{1} \mathrm{H}$ NMR's study of Rhodamine-derivative I structure agrees with the assigned structure. At low fields there are four protons (7.89, 7.55, 7.49 and $7.18 \mathrm{ppm})$ of the ring of benzothiolane-2-one with their expected multiplicity, followed by two singlets (6.55 and $6.36 \mathrm{ppm}$ ), corresponding to the protons of the xanthene ring, and the resonances of the groups N-Et (3.23 ppm and $1.34 \mathrm{ppm}$ ) and Me (1.98 ppm). A second set of signals appears in the ${ }^{1} \mathrm{H}$ NMR spectrum, probably due to the balance with the opened structure, which appears in approximately $20 \%$ in chloroform. The spectrum of ${ }^{13} \mathrm{C}$ NMR shows also relevant signals, as the resonance at $62.8 \mathrm{ppm}$, that is assigned to the quaternary carbon of the spiranic bridge, and at $197.90 \mathrm{ppm}$, assigned to CO-S.

\subsection{Chemicals and Reagents}

All chemical and solvents used in this study were of analytical grade. Ultra pure water was provided by use of a Millipore Milli-Q system (Millipore, Bedford, MA, USA).

Mercury chloride (II) was obtained from Panreac. The standard stock solution of mercury (II) $(1 \mathrm{mM})$ and the HEPES buffer (Sigma) 0.02 M (pH 7.4) were prepared in ultra pure water. The Rhodamine-derivative I $\left(10^{-3} \mathrm{M}\right)$ was prepared in acetonitrile. Diluted solutions of the stock solutions were prepared by appropriate dilution.

Standard Reference Material 1641d was purchased from NIST, containing $1.557 \pm 0.020 \mathrm{mg} / \mathrm{kg}$ of $\mathrm{Hg}^{2+}$.

\subsection{Apparatus}

UV-Vis measurements were performed using a Spectrophotometer Varian Model Cary 50 Bio, equipped with a Xenon lamp.

For the studies of the influence of physical and chemical variables on the reaction, fluorescence measurements were performed using a Fluorescence Spectrophotometer Varian Model Cary Eclipse, equipped with a Xenon flash lamp. Excitation and emission bandwidths of $2.5 \mathrm{~nm}$ were used in these studies. Intensity was measured at 554 $\mathrm{nm}$ (excitation at $527 \mathrm{~nm}$ ), which is the emission maximum of the complex Rhodamine-derivative $\mathbf{I}-\mathrm{Hg}^{2+}$. All measurements were performed in $10 \mathrm{~mm}$ quartz cells at $10^{\circ} \mathrm{C}$, by use of a thermostatically controlled cell holder and a Selecta Model 382 thermostatically controlled water-bath.

On the other hand, a portable instrument AvaSpec2048-USB2-SPU was used. The instrument is equipped with a Cerny-Turner symmetric monocromator, with 75 $\mathrm{mm}$ of focal distance, and a CCD detector of 2048 pixels connected to an USB2 interface. A Prizmatix BlackLED-515, exciting at $515 \mathrm{~nm}$ (spectrum half width 36 $\mathrm{nm}$ ), equipped with a filter Omega Optical 525AF45 (XF1074), to suppress the emission of LED further than $525 \mathrm{~nm}$, was employed. The AvaSoft Full Software was used for data acquisition and analysis. All measurements were carried out after 5 minutes of turning on the LED to ensure a constant operating temperature.

${ }^{1} \mathrm{H}$ and ${ }^{13} \mathrm{C}$ NMR spectra were recorded on a Bruker $400 \mathrm{AC} / \mathrm{PC}$ instrument at 400 and $100 \mathrm{MHz}$, respectively in $\mathrm{CDCl}_{3}$. Assignments were confirmed by homo- and hetero-nuclear double-resonance, DEPT (distortionless enhancement by polarization transfer). TMS was used as the internal standard $(\delta=0.00 \mathrm{ppm})$ and all $\mathrm{J}$ values are given in Hz. A Crison MicropH 501 meter was used for $\mathrm{pH}$ measurements.

\subsection{General Procedure for Fluorescence Measurements}

In a fluorescence cell, $30 \mu \mathrm{L}$ of Rhodamine-derivative I in acetonitrile $\left(10^{-3} \mathrm{M}\right)$ were placed. Later, an aliquot of the mercuric ion stock solution $(1 \mathrm{mM})$ to give the final concentration desired is added, followed by $1.5 \mathrm{~mL}$ of HEPES buffer (0.02 M, pH 7.4). Then, the solution was diluted with ultra pure water to complete $3 \mathrm{~mL}$, and the fluorescence was measured at $554 \mathrm{~nm}$ (excitation at 527 $\mathrm{nm}$ ) in the Varian spectrofluorimeter or at $555 \mathrm{~nm}$ (excitation at $515 \mathrm{~nm}$ ) in the portable instrument.

For the determination of mercury (II) at low concentrations, a mercury (II) stock solution of $10 \mu \mathrm{M}$ was prepared, by diluting the original stock solution, and proper amounts of this solution were used in the analytical procedure. In those cases, fluorescence measurements were carried out after addiction of $\mathrm{Hg}^{2+}$ for $5 \mathrm{~min}$.

\subsection{Procedure for Determination of Mercury(II) in Certified Samples}

In a fluorescence cell, $30 \mu \mathrm{L}$ of Rhodamine-derivative I in acetonitrile $\left(10^{-3} \mathrm{M}\right)$ was placed. Later, an aliquot of the certified sample (Standard Reference Material 1641d) to give the final concentration desired is added $(155 \mu \mathrm{L})$, followed by $1.5 \mathrm{~mL}$ of HEPES buffer (0.02 M, pH 7.4), and ultra pure water to complete $3 \mathrm{~mL}$. The fluorescence was measured at $555 \mathrm{~nm}$ (excitation at $515 \mathrm{~nm}$ ) in the portable instrument. 


\section{Results and Discussion}

\subsection{Conventional Spectrofluorimeter}

At first, the spectral characteristics of the Rhodaminederivative I were studied. The compound is red-colored but is non-fluorescent, probably due to its stable "spirolactam form" [25]. The absorbance spectra of the Rhodamine-derivative $\mathrm{I}$ in absence and in the presence of 10 $\mu \mathrm{M}$ of $\mathrm{Hg}^{2+}$ is shown in Figure 1. The absorption spectrum of Rhodamine-derivative $\mathbf{I}$ is showing a high increment of its absorbance in the presence of $\mathrm{Hg}^{2+}$, giving absorption maxima at $500 \mathrm{~nm}$ and $525 \mathrm{~nm}$. On the other hand, the fluorescence emission spectra of Rhodaminederivative $\mathbf{I}$, in the absence and presence of different amounts of mercury (II), are shown in Figure 2. It can be seen that the Rhodamine-derivative I displays no obvious spectral characteristics in its emission spectra. However, a significant enhancement of fluorescence, with an excitation maximum at $527 \mathrm{~nm}$, and an emission maximum at $554 \mathrm{~nm}$ was observed, when mercury (II) was added. A spectral red shift of $7 \mathrm{~nm}$ was observed in the emission maxima with the increase of the concentration of mercury (II).

The effect of temperature was studied between the range $5^{\circ} \mathrm{C}-40^{\circ} \mathrm{C}$. It could be observed a quenching of fluorescence when the temperature increases. Also, the effect of Rhodamine-derivative I concentration on the fluorescence intensity was investigated. Figure $\mathbf{3}$ shows that a maximum fluorescence enhancement was observed

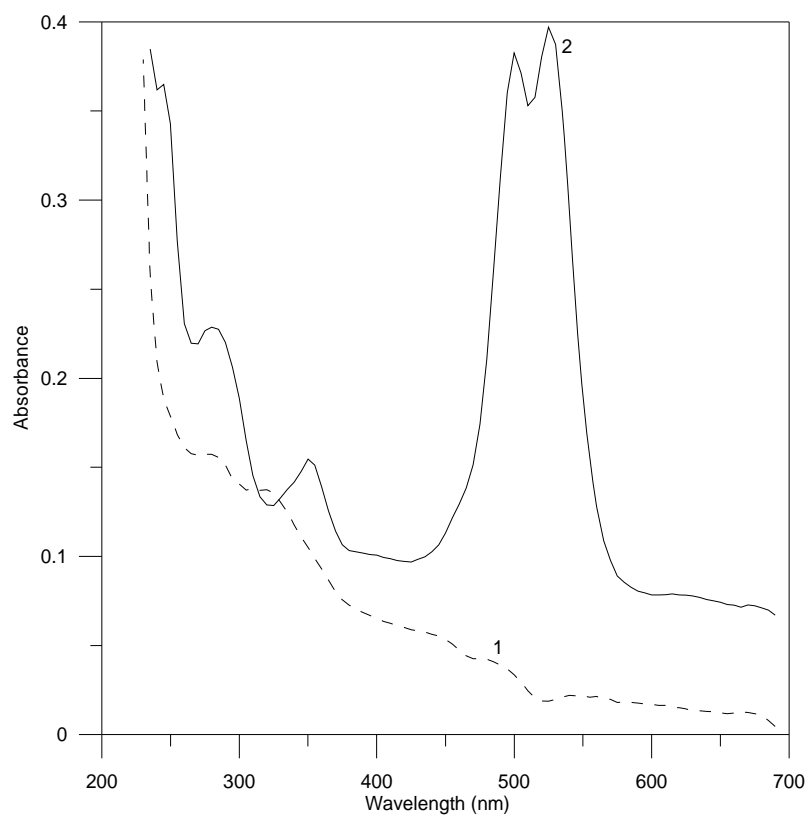

Figure 1. Absorbance spectra of Rhodamine-derivative $I$ in the absence (1) and in the presence (2) of $\mathrm{Hg}^{2+}$. [Rhodamine-derivative $\mathrm{I}]=\left[\mathrm{Hg}^{2+}\right]=10 \mu \mathrm{M}$.

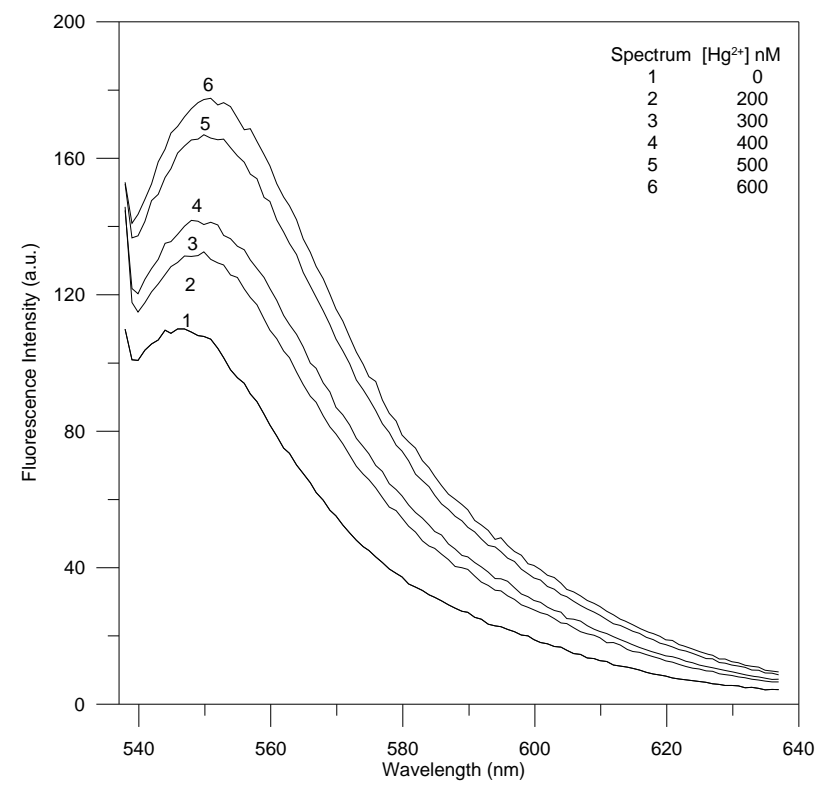

Figure 2. Emission spectra of Rhodamine-derivative $I$ in the absence and the presence of different amounts of $\mathrm{Hg}^{2+}$. [Rhodamine-derivative I] $=10 \mu \mathrm{M} ; \lambda_{\mathrm{exc}}=527 \mathrm{~nm}$.

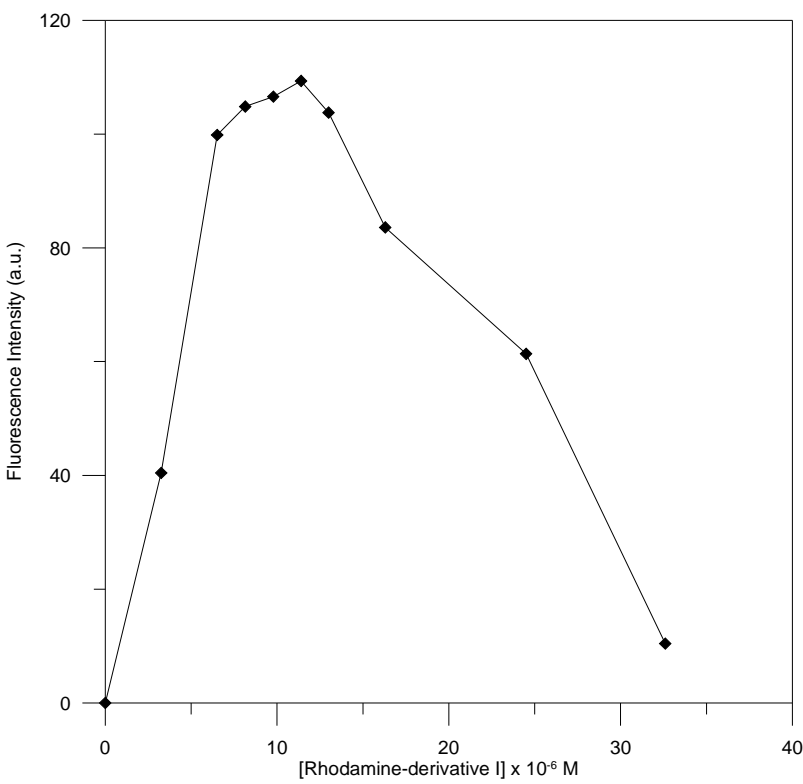

Figure 3. Influence of the concentration of Rhodaminederivative $I$ on the fluorescence intensity of the complex. $\left[\mathrm{Hg}^{2+}\right]=10 \mu \mathrm{M}$.

when $10 \mu \mathrm{M}$ of Rhodamine-derivative I reacted with 10 $\mu \mathrm{M}$ of mercury (II) in HEPES buffer 7.4 for $5 \mathrm{~min}$, so 10 $\mu \mathrm{M}$ was chosen for further experiments.

Also, the addition order was studied being Rhodamine-derivative $\mathbf{I}+\mathrm{Hg}^{2+}+$ HEPES buffer + water the one which shows maximum fluorescence intensity. The proposed binding mode between Rhodamine-derivative I and $\mathrm{Hg}^{2+}$ is shown in Scheme 1. The large fluorescence 
enhancement can be attributed to a ring-opening process of the spirothiolactone ring, and the complexation with $\mathrm{Hg}^{2+}$ in a 2:1 stoichiometric ratio. The evidences of the binding mode were previously reported, based in ESIMS spectra and X-ray analysis [29].

The 2:1 stoichiometry was also confirmed by the classical method of Job.

An interference study was performed to evaluate the selectivity of the reagent. $\mathrm{Cu}^{2+}, \mathrm{Ni}^{2+}, \mathrm{Zn}^{2+}, \mathrm{Cd}^{2+}, \mathrm{Co}^{2+}$, $\mathrm{Cs}^{+}, \mathrm{Li}^{+}, \mathrm{Ca}^{2+}, \mathrm{Mn}^{2+}, \mathrm{K}^{+}, \mathrm{Na}^{+}, \mathrm{Sr}^{2+}, \mathrm{Fe}^{2+}, \mathrm{Rb}^{+}, \mathrm{Al}^{3+}, \mathrm{Mg}^{2+}$, $\mathrm{Cr}^{3+}$ and $\mathrm{Pb}^{2+}$ did not interfere at $100 \mu \mathrm{M}$ concentration level. Only $\mathrm{Ag}^{+}$gave a small fluorescence signal at that level.

\subsection{Portable Spectrofluorimeter (LED-fluorescence)}

In order to obtain high excitation efficiency, the emission wavelength of LED had to match the excitation wavelength of the complex Rhodamine-derivative $\mathbf{I}: \mathrm{Hg}^{2+}$. Therefore, the excitation wavelength of the LED should be chosen carefully. As it could be seen in Figure 2, in the conventional spectrofluorimeter, the complex produced high fluorescence with a maximum excitation at
$527 \mathrm{~nm}$ and a maximum emission at $554 \mathrm{~nm}$. Because the fluorescent complex has only a small Stoke's shift $\left(\lambda_{\mathrm{em}}-\lambda_{\mathrm{exc}}=27 \mathrm{~nm}\right)$, if the maximum wavelength of LED approaches the fluorescence emission of the complex, then their spectra overlap phenomenon will be serious. For this reason, a LED with a maximum at $515 \mathrm{~nm}$ and a $525 \mathrm{~nm}$ interference filter were used, in order to avoid overlapping of the spectra. Figure 4 shows the emission spectra of the complex recorded in the portable spectrofluorimeter at optimum conditions.

According to the procedure developed for the conventional spectrofluorimeter, the calibration curve for the determination of mercury (II) was constructed in the portable instrument, under the optimum conditions. The linear range was $0-600 \mathrm{nM}$, with a correlation coefficient of $R^{2}=0.9968(n=15)$. The regression parameters are summarized in Table $\mathbf{1 .}$

The detection limit, based on the definition by IUPAC [30] $\left(\mathrm{LOD}=3 \mathrm{~S}_{\mathrm{b}} / \mathrm{m}\right)$, was found to be $28 \mathrm{nM}$ from 10 blank solutions and $32 \mathrm{nM}$, according to the Clayton criterium, taking into account the probabilities of false positive and false negative type errors [31]. The relative standard deviation (R.S.D.) for ten repeated measurements of $400 \mathrm{ng} \cdot \mathrm{mL}^{-1}$ of mercury (II) was $1.4 \%$.

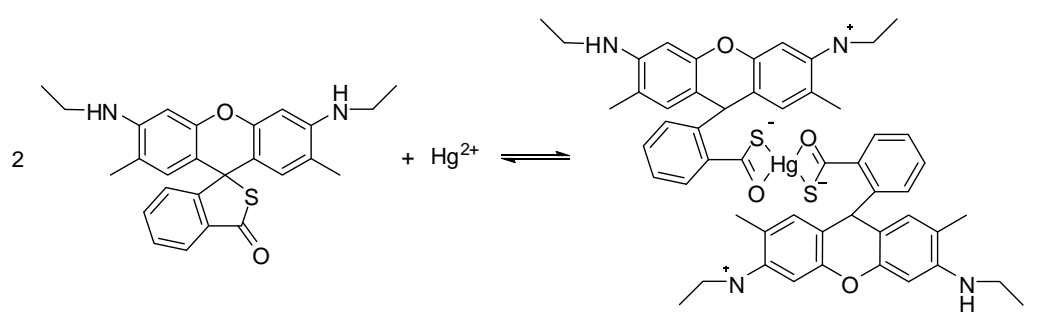

Scheme 1. Proposed binding mode between Rhodamine-derivative I and $\mathbf{H g}^{2+}$.

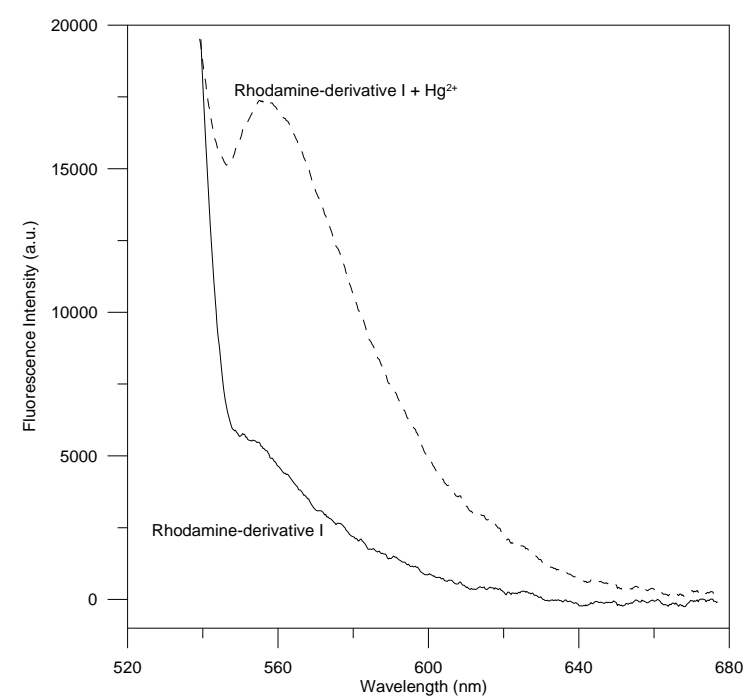

Figure 4. Emission spectra of the complex formed between Rhodamine-derivative $\mathrm{I}$ and $\mathrm{Hg}^{2+}$ recorded in the portable instrument. $[$ Rhodamine-derivative $\mathrm{I}]=\left[\mathrm{Hg}^{2+}\right]=10 \mu \mathrm{M} ; \lambda_{\mathrm{exc}}=515 \mathrm{~nm}$. 
Table 1. Regression parameters for the determination of mercury (II) in the portable instrument.

\begin{tabular}{lc}
\hline & Portable \\
\cline { 2 - 2 } Linear range $(\mathrm{nM})$ & $0-600$ \\
Slope $(\mathrm{nM})$ & 5561 \\
Intercept & 16.3 \\
St. Dev. of slope & 87 \\
St. Dev. of Intercept & 0.3 \\
Linearity (\%) & 98.4 \\
RSD (\%) $(n=10)$ & 1.4 \\
$\mathrm{R}^{2}$ & 0.9968 \\
LOQ (IUPAC), nM & 93 \\
LOD (IUPAC), nM & 28 \\
LOD* (Clayton, $\alpha=\beta=0.05), \mathrm{nM}$ & 32 \\
\hline${ }^{*}$ LOD according to the criterium of Clayton et al. (Ref. 31)
\end{tabular}

The proposed method was validated by application to the certified sample Standard Reference Material 1641d. Three replicates were analyzed and satisfactory results were found with the portable instrument, suggesting the potential application of the reagent for the better analysis of environmental water samples.

\section{Conclusions}

In conclusion, the Rhodamine $6 \mathrm{G}$ monothiolactone derivative was synthesized and characterized. Its absorptiometric and fluorimetric properties, in absence and in the presence of $\mathrm{Hg}^{2+}$, were established, and a calibration study was performed and validated by using of a certified sample reference material. A suitable method for "in situ" analysis of $\mathrm{Hg}^{2+}$ was developed, using a portable instrument, composed of a $515 \mathrm{~nm}$ LED as excitation source, two fiber optics and a CCD camera as detector. The high selectivity of the method towards other metal ions was corroborated by an interference study.

\section{Acknowledgements}

This work was supported by the Ministerio de Ciencia e Innovación of Spain (Project CTQ2011-25388) and the Junta de Extremadura (Consolidation Project GR10033 of Research Group FQM003 co-financed by European FEDER Funds).

\section{References}

[1] J. E. Sánchez Uria and A. Sanz-Medel, "Inorganic and Methylmercury Speciation in Environmental Samples," Talanta, Vol. 47, No. 3, 2008, pp. 509-524.

[2] M. Morita, J. Yoshinaga and J. S. Edmonds, “The Determination of Mercury Species in Environmental and Biological Samples," Pure \& Applied Chemistyr, Vol. 70, No. 8, 1998, pp. 1585-1615.

\section{doi:org/10.1351/pac199870081585}

[3] E. M. Nolan and S. J. Lippard, "A "Turn-On" Fluorescent Sensor for the Selective Detection of Mercuric Ion in Aqueous Media," Journal of the American Chemical Society, Vol. 125, No. 47, 2003, pp. 14270-14271. doi:org/10.1021/ja037995g

[4] E. M. Nolan and S. J. Lippard, "Turn-On and Ratiometric Mercury Sensing in Water with a Red-Emmiting Probe," Journal of the American Chemical Society, Vol. 129, No. 18, 2007, pp. 5910-5918. doi:org/10.1021/ja068879r

[5] E. M. Nolan, M. E. Racine and S. J. Lippard, "Selective $\mathrm{Hg}$ (II) Detection in Aqueous Solution with Thiol Derivatized Fluoresceins," Inorganic Chemistry, Vol. 45, No. 6, 2006, pp. 2742-2749. doi:org/10.1021/ic052083w

[6] H. J. Kim, J. E. Park, M. G. Choi, S. Ahn and S. K. Chang, "Selective Chromogenic and Fluorogenic Signalling, of $\mathrm{Hg}^{2+}$ Ions Using a Fluorescein-Coumarin Conjugate," Dyes and Pigments, Vol. 84, No. 1, 2010, pp. 54-58. doi:org/10.1016/j.dyepig.2009.06.009

[7] Y. Jin, I. Yoon, J. Seo, J. E. Lee, S. T. Moon, J. Kim, S. W. Han, K. M. Park, L. F. Lindoy and S. S. Lee, "Cadmium(II) and Mercury(Ii) Complexes of an $\mathrm{NO}_{2} \mathrm{~S}_{2}$-Donor Macrocycle and Its Ditopic Xylyl-Bridged Analogue," Dalton Transactions, Vol. 4, 2005, pp. 788-796. doi:org/10.1039/b415794j

[8] J. Wang and X. Qian, "Two Regioisomeric and Exclusively Selective $\mathrm{Hg}(\mathrm{II})$ Sensor Molecules Composed of a Naphthalimide Fluorophore and an O-Phenylenediamine Derived Triamide Receptor," Chemical Communication, Vol. 1, 2006, pp. 109-111. doi:org/10.1039/b511319a

[9] Q. Meng, X. Zhang, C. He, P. Zhou, W. Su and C. Duan, "A Hybrid Mesoporous Material Functionalized by 1,8-Naphthalimide-Base Receptor and the Application as Chemosensor and Absorbent for $\mathrm{Hg}^{2+}$ in Water," Talanta, Vol. 84, No. 1, 2011, pp. 53-59.

doi:org/10.1016/j.talanta.2010.12.008

[10] J. Wang and X. Qian, "A Series of Polyamide Receptor Based PET Fluorescent Sensor Molecules: Positively Cooperative $\mathrm{Hg}$ Ion Binding with High Sensitivity," Organic Letters, Vol. 8, No. 17, 2006, pp. 3721-3724. 
doi:org/10.1021/o1061297u

[11] J. Du, J. Fan, X. Peng, H. Li, J. Wang and S. Sun, "Highly Selective and Anions Controlled Fluorescent Sensor for $\mathrm{Hg}^{2+}$ in Aqueous Environment," Journal of Fluorescence, Vol. 18, No. 5, 2008, pp. 919-924. doi:org/10.1007/s10895-008-0324-3

[12] H. J. Kim, S. H. Kim, J. H. Kim, E. H. Lee, K. W. Lim and J. S. Kim, "BODIPY Appended Crown Ethers: Selective Fluorescence Changes for $\mathrm{Hg}^{2+}$ Binding," Bulletin of the Korean Chemical Society, Vol. 29, No. 9, 2008, pp. 1831-1834. doi:org/10.5012/bkcs.2008.29.9.1831

[13] Y. K. Yang, K. J. Yook and J. Tae. "A Rhodamine-Based Fluorescent and Colorimetic Chemodosimeter for the Rapid Detection of $\mathrm{Hg}$ Ions in Aqueous Media," Journal of the American Chemical Society, Vol. 127, No. 48, 2005, pp. 16760-16761. doi:org/10.1021/ja054855t

[14] X. Q. Zhan, Z. H. Qian, H. Zheng, B. Y. Su, Z. Lan and J. G. Xu, "Rhodamine Thiospirolactone. Highly Selective and Sensitive Reversible Sensing of $\mathrm{Hg}(\mathrm{II})$," Chemical Communication, Vol. 16, 2008, pp. 1859-1861. doi:org/10.1039/b719473k

[15] W. Shi and H. Ma, "Rhodamine B thiolactone: a Simple Chemosensor for $\mathrm{Hg}^{2+}$ in Aqueous Media," Chemical Communication, Vol. 16, 2008, pp. 1856-1858. doi:org/10.1039/b717718f

[16] S. K. Ko, Y. K. Yang, J. Tae and I. Shin, "In vivo Monitoring of Mercury Ions Using a Rhodamine-Based Molecular Probe," Journal of the American Chemical Society, Vol. 128, No. 43, 2006, pp. 14150-14155. doi:org/10.1021/ja065114a

[17] H. Zheng, Z. H. Qian, L. Xu, F. F. Yuan, L. D. Lan and J. G. Xu, "Switching the Recognition Preference of RhoDamine B Spirolactam by Replacing One Atom: Design of Rhodamine B Thiohydrazide for Recognition of $\mathrm{Hg}(\mathrm{II})$ in Aqueous Solution," Organic Letters, Vol. 8, No. 5, 2006, pp. 859-861. doi:org/10.1021/o10529086

[18] X. Q. Zhan, Z. H. Qian, H. Zheng, B. Y. Su, Z. Lan and J. G. Xu, "Rhodamine Thiospirolactone. Highly Sensitive Reversible Sensing of $\mathrm{Hg}^{2+}$," Chemical Communication, 2008, pp. 1859-1861.

[19] H. N. Kim, S. W. Nam, K. M. K. Swamy, J. Yan, X. Chen, Y. Kim, S. J. Kim, S. Park and J. Yoon, "Rhodamine Hydrazone Derivatives as $\mathrm{Hg}^{2+}$ Selective Fluorescent and Colorimetric Chemosensors and Their Applications to iBoimaging and Microfluidic System," Analyst, Vol. 136, No. 7, 2011, pp. 1339, 1343.

[20] Y. K. Yang, S. K. Ko, I. Shin and J. Tae, "Fluorescent Detection of Methylmercury by Desulfurization Reaction of Rhodamine Hydrazide Derivatives," Organic and
Biomolecular Chemistry, Vol. 7, No. 22, 2009, pp. 4590-4593.

doi:org/10.1039/b915723a

[21] D. Bohoyo-Gil, M. I. Rodríguez-Cáceres, M. C. HurtadoSánchez and A. Muñoz de La Peña, "Fluorescent Determination of $\mathrm{Hg}^{2+}$ in Water and Fish Samples Using a Chemo-Dosimeter Based in a Rhodamine 6G Derivative and a Portable-Optic Spectrofluorimeter,' Applied Specifications, Vol. 64, No. 5, 2010, pp. 520-527.

[22] A. Muñoz de la Peña, M. I. Rodríguez-Cáceres, M. C. Hurtado-Sánchez and D. Bohoyo Gil, "A Novel Application of $\mathrm{Hg}^{2+}$ Based in a Spirocyclic Rhodamine 6G Phenyl-Thiosemicarbazide Derivative," Luminiscence, Vol. 25, 2010, pp. 229-230.

[23] B. N. Ahamed and P. Ghosh, "An Integrated System of Pyrene and Rhodamine-6G for Selective Colorimetric and Fluorometric Sensing of Mercury(II)," Inorganica Chimicia Acta, 2011, doi:10.1016/j.ica.2011.01.071.

[24] Y. Gabe, Y. Urano, K. Kikuchi, H. Kojima and T. Nagano, "Highly Sensitive Fluorescence Probes for Nitric oxide Based on Boron Dipyrromethene Chromophore Rational Design of Potentially Useful Bioimaging Fluorescence Probe," Journal of the American Chemical Society, Vol. 126, No. 10, 2004, pp. 3357-3367. doi:org/10.1021/ja037944j

[25] T. Nguyen and M. B. Francis, "Practical Synthetic Route to Functionalized Rhodamine Dyes," Organic Letters, Vol. 5, No. 18, 2003, pp. 3245-3248. doi:org/10.1021/o1035135z

[26] M. A. Khan, "AlGaN Multiple Quantum Well Based Deep UV LEDs and Their Applications," Solid State Physics, Vol. 203, No. 7, 2006, pp. 1764-1770. doi:org/10.1002/pssa.200565427

[27] E. F. Schubert, "Light-Emitting Diodes", Cambridge University Press (UK), Cambridge, 2003

[28] S. Landgraf, "Application of Semiconductor Light Sources for Investigations of Photochemical Reactions," Spectrochimica Acta A, Vol. 57, No. 10, 2001, pp. 20292048. doi:org/10.1016/S1386-1425(01)00502-9

[29] X. Chen, S. W. Nam, M. J. Jou, Y. Kim, S. J. Kim, S. Park and J. Yoon, " $\mathrm{Hg}^{2+}$ Selective Fluorescent and Colorimetric Sensor: Its Crystal Structure and Application to Bioimaging," Organic Letters, Vol. 10, No. 22, 2008, pp. 5235-5238. doi:org/10.1021/o18022598

[30] H. M. Irving, H. Freiser and T. S. West, "IUPAC Compendium of Analytical Nomenclature, Definitive Rules," Pergamon Press, Oxford, 2004.

[31] C. A. Clayton, J. W. Hines and P. D. Elkins, "Detection limits with Specified Assurance Probabilities," Analytical Chemistry, Vol. 59, No. 20, 1987, pp. 250. doi:org/10.1021/ac00147a014 